\title{
Cultivating Ethics - A perspective from practice
}

\author{
Sharon Lindberg \\ sharon@dsv.su.se \\ Department of Computer and Systems \\ Sciences, Stockholm University \\ Kista, Sweden
}

\author{
Petter Karlström \\ petter@dsv.su.se \\ Department of Computer and Systems \\ Sciences, Stockholm University \\ Kista, Sweden
}

\author{
Sirkku Männikkö Barbutiu \\ sirkku@dsv.su.se \\ Department of Computer and Systems \\ Sciences, Stockholm University \\ Kista, Sweden
}

\begin{abstract}
Ethically responsible design of technology has been under prolific discussion in recent years. Since design practitioners play a big part in shaping technology, their understanding of ethics is important. Much research has been conducted on ethics in design, but research findings are rarely used in industry. Our study addresses this gap by creating a space for conversation for design practitioners to explore the meaning of design ethics and related challenges. Our findings confirm the complexity of integrating ethics into the everyday practice of design, and suggest co-creating possible solutions as a way to start cultivating ethos in practice. Practitioners envisioned ideas for a toolbox concept, thoughts on how to integrate ethics into existing practices, and a visual moral compass. Our findings translate into a set of questions aiming to make ethical issues in practice visible, and to stimulate discussions around what designers considered to be ethical challenges.
\end{abstract}

\section{CCS CONCEPTS}

\section{- Human-centered computing $\rightarrow$ Empirical studies in $\mathrm{HCI}$.}

\section{KEYWORDS}

Design ethics, design practice, practitioner, ethos building

\section{ACM Reference Format:}

Sharon Lindberg, Petter Karlström, and Sirkku Männikkö Barbutiu. 2020. Cultivating Ethics - A perspective from practice. In Proceedings of the 11th Nordic Conference on Human-Computer Interaction: Shaping Experiences, Shaping Society (NordiCHI '20), October 25-29, 2020, Tallinn, Estonia. ACM, New York, NY, USA, 11 pages. https://doi.org/10.1145/3419249.3420064

\section{INTRODUCTION}

With technology affecting so many aspects of life, the ethical responsibilities of designers of technology have rapidly increased. "Now is our moment to change the practice of design to improve the ethics of design" urges Shilton [33], joining scholars and design practitioners alike who argue for ethically responsible design $[1,7,9,17-19,23,30]$.

While there is a growing urgency to the matter of ethics in design, the significance of the area is not new. There have been several

Permission to make digital or hard copies of all or part of this work for personal or classroom use is granted without fee provided that copies are not made or distributed for profit or commercial advantage and that copies bear this notice and the full citation on the first page. Copyrights for components of this work owned by others than the author(s) must be honored. Abstracting with credit is permitted. To copy otherwise, or republish, to post on servers or to redistribute to lists, requires prior specific permission and/or a fee. Request permissions from permissions@acm.org.

NordiCHI '20, October 25-29, 2020, Tallinn, Estonia

(c) 2020 Copyright held by the owner/author(s). Publication rights licensed to ACM ACM ISBN 978-1-4503-7579-5/20/10 ..\$15.00

https://doi.org/10.1145/3419249.3420064 calls to action, addressed from multiple angles, such as theories and methods [6,11,37, 38], tools [16], societal consequences of design $[1,21,27]$, design ethics in practice $[7,15,19,23,25,30]$, codes of conduct [8, 23], manifestos [18], games [22], frameworks [10], and various other initiatives $[9,13,17,29]$.

There is an abundance of e.g. guidelines, recommendations, rules and initiatives for ethically responsible design, but results and propositions from academia seem to be underused in practice $[3,5,26,33]$. This is, of course, unfortunate and wasteful - research results do take many forms that are intended to be applicable for designers, and there is a rising demand from designers for support for acting ethically. One may ask why research and practice do not align more. One reason, according to practitioners, is that academic research results are not in forms that can readily be used in practice [26]. But if the interests of academia and practice align, and if the intent from research is to be applicable, there seems to be a gap in communication. One way to bridge this gap is to involve practitioners in the development of solutions, and to do so by way of design-oriented manners.

The approach that our present study has taken is practice oriented, specifically regarding ethos cultivation. From the abundant literature above, we primarily draw on the work of Frauenberger, Rauhala and Fitzpatrick [10], who discuss ethos as a "moral commitment or stance" which is co-constructed and continuously renegotiated. They argue that since traditional, formal ethics and related guidelines are not sufficient on their own to manage today's ethical dilemmas in HCI, and since ethics is continuously in formation, ethics needs a more dynamic approach. This means that instead of just following rules and guidelines, ethics should be co-constructed continuously in reflective practice. Another key point is that ethical awareness is important and relevant for all actors and in all processes. They call their proposed approach 'In-Action Ethics' and frame it in the feminist concept of care, thus embedding ethos building in responsibility, relationships, moral sensitivity, attentiveness, and connectedness.

While they focus on the practice of HCI research, they also suggest this approach to be constructive outside of academia, which aligns with HCI:s growing interest in examining real-life practices [20]. Adhering to this turn to practice, we argue that feasible solutions to real-world challenges in design practice should require engagement with the people on the ground, i.e. designers. If academic research is to participate in developing ethically responsible design practices, it should be important to know how designers themselves approach ethics, and what kind of solutions they envision as viable ways forward.

Recognizing the practice turn and emerging urge for ethical considerations in design work, the aim of this inquiry is to investigate ethos cultivation, i.e. how ethical practices can be cultivated among 
designers of technology. If ethics is to be an "underpinning mindset" [10], the cultivation of ethics should be that too. Without purposeful cultivation, skills and practices will still transform over time whether we want it or not, but by devotedly engaging in cultivating them, there is a higher chance that they evolve towards the vision we are striving for: ethically responsible design of technology. Our study is exploring how this could be done.

For a more neutral approach to ethos building in practice, we did not design our study around any particular academic standpoint to ethics. Our interest has been in the 'soil' for cultivating ethos rather than in introducing and testing available ethical frameworks or methodologies. In order to bridge the research-practice gap in design practice, we need to know more about how designers view ethical challenges and their solutions. That is to say that our intended contribution was not to find directly applicable solutions regarding ethical design, but to find applicable points of departure for such solutions.

By conducting a workshop with design practitioners, we were able to tap into their practices and enquire into their view on ethics in their work. Our research question was: 'How would designers conduct cultivation of their own ethical practices?', supported by the questions: 'What would their starting points be?' and 'What would their suggestions for solutions look like?'.

Our contribution is to present points of departure in order to bridge the gap between research and practice, rather than to provide exhaustive solutions. First, we provide insights on how designers understand and wish to solve ethical issues related to their work. Second, we present designers' proposals and ideas on ethos building in design practices. Third, we build on this input from design practice to form an actionable set of questions to be put to use at suitable junctures in studio practice. The results would be useful for anyone interested in cultivating ethical design practices, whether from a scholarly perspective or a practice one.

\section{FRAMING THE ISSUE}

The focus of our investigation lies in the 'ethics of design' with the starting point in 'practices' that are changing over time. To change the practice of design to improve the ethics of design [33] (cultivating ethos), there are a few concepts that need clarification: What do we mean by 'practice'? How can we approach the 'changing' of practice? And what does 'ethics of design', which we are striving to improve, mean?

\subsection{Practice}

We agree with Schatztki [31] in the realisation that "the field of practice is the place to investigate phenomena such as agency, knowledge, language, ethics, power and science". Schatzki [31] states that practice knowledge is situated, context-related and embodied. This means that knowledge is often not the property of individuals, but of groups together with their material setups. In other words: practices can be viewed as the carrier of meaning, language, and normativity, and are shaped by and shape the groups and materials involved. Practices are also formed by the visions of practitioners of what is the right thing to do in a particular situation.

Wenger, McDermott and Snyder [40] emphasise the collective aspect of 'practice' consisting of different practice communities: "groups of people who share a concern, a set of problems, or a passion about a topic, and who deepen their knowledge and expertise in this area by interacting on an ongoing basis". People in communities typically share information and advice, and talk about their situations, goals and needs. They explore ideas, and may construct tools and solutions as well as develop shared tacit understandings. Communities of practice are not standalone entities, but connected, and can link people across business units as well as from different organizations, both locally and globally. Communities of practice is not a new idea; gathering around concerns, problems and/or interests is certainly a core part in human knowledge construction. However, what we gather around changes over time, both when it concerns work and in our private lives.

Shove, Pantzar and Watson [34] draw on work from e.g. Schatzki and Reckwitz, looking into the dynamic aspects of social practice in an aim to comprehend social change and stability. They describe practice-as-entity and practice-as-performance. This means understanding 'practice' both as as a block or pattern consisting of related elements such as e.g. bodily and mental activities, background knowledge, know-how and motivations, and as performances i.e. that individuals are the carriers of a practice through their performance. They present a framework based on three elements: materials, competence and meaning. Materials refer to things (e.g. technologies or tangible physical entities), since materials as well as people can shape practice, as also described by e.g. Pickering [28]. Competence refers to practical knowledgeability, and meaning refers to social as well as symbolic significance of participation [34]. In the case of a design studio, this entails that e.g. designers, managers, and clients, as well as e.g. documents, software, hardware and prototyping materials, and e.g. skills, beliefs, and emotions are all part of shaping practice in interplay with one another.

In short, our perspective on practice is that it consists of distributed, connected, and co-constructed knowledge, mental as well as bodily activities, materials, ways of doing things, and is continuously in formation.

\subsection{Changing practice}

Practices are not static but change over time - we pick up ideas from here and there, and make new connections between existing ideas and practices as needed [34]. What do we mean when we say that a practice has changed? It can mean e.g. what we do, how we do it, what tools or other artefacts we use to do things, how we think and feel about what we do, and/or what we know about it changes. This also implies a view of knowledge as social as well as individual, and as dynamic: "it is continually in motion" [40].

Shove et al. [34] discuss the recruitment, defection and reproduction of practices. There are several reasons to why a person would end up carrying particular practices, at work as well as in life in general, and there are several reasons that a practice can be changed or abandoned. An important point is that evolving practices commonly change their networks as well as who they do and do not include [34], in other words: change is normal. Changing a practice can be approached as promoting transitions in practice and to configure elements of practice, the elements being material, competence and meaning, as mentioned above [34]. 
Cultivation is the term used by Wenger et al. [40], and its goal in this context is to influence communities into achieving their full potential. To cultivate something means to provide the right circumstances. For seeds, it may involve to prepare the soil with the right nutrients and micro-organisms, adding just enough water, and making sure that the right amount of light is available. Similarly, for communities of practice, organizations can do a lot to create an environment in which the communities can prosper. The way to do it is through negotiation, and it has more to with inspiring and scaffolding participation than organizing and managing their activities [40].

We adhere to the view of eliciting and fostering participation as a beneficial way of deliberately changing practices (compared to directing or organizing 'from above').

\subsection{Ethics of design}

What is meant when we say 'ethics' in the context of design? It has been suggested to incorporate the choice of what to design at all, the object of design, and the ethical impact of a finished design. [4]. Often, 'design ethics' signifies the analysis of ethical concepts or principles in design [4].

Many particularities in ethics related to design have been discussed over the years, such as the relationship between the values of designers and design outcomes [11,32], the role of ethicists in design [36], ethics in design education [12], ethical research practices [24], and agency of designers as well as technical artifacts [32, 37], just to mention a few.

General methods related to ethics and design have been explored as well, for example Value Sensitive Design (VSD) [11] has been under prolific development and discussion for quite some time. Several other ethical tools such as the ethical matrix, delphi, forecasting and back-casting, and responsibility analysis, have also been suggested as possible solutions for ethical dilemmas related to technology design [16].

Walsh [39] does not deal with design practices per se, but his arguments should nonetheless be relevant in design practice as well. Walsh argues that people today have marginalized ethics, having a tendency to believe it only to be relevant in special narrow circumstances. But, he argues, ethics is important every day. Walsh stresses that doing ethics means doing work: "debating, talking, listening, understanding, respecting and in many cases, troubling the status quo and being uncomfortable".

This aligns with the concept of ethos building of Frauenberger, Rauhala and Fitzpatrick [10], and their argument that "ethics is necessarily co-constructed". It should, however, not be understood as moral relativism but as a recognition of the local preconditions and traditions which should be central in ethos cultivation.

Gray and Chivukula [14] provide an account of how UX designers reflect on ethics in practice. They propose a framework for analyzing relationships that affect ethically-informed action, one example being that organizational practices can constrain what the individual does - but an individual's actions can also change organizational practice.

In summation: our stance on design ethics is that it needs to be co-constructed and continuously negotiated in reflective practice.

\section{OUR SETTING - A DESIGN STUDIO}

For our investigation of ethics and ethos cultivation in design practice, we turned to a design studio in Stockholm, Sweden. It is a well-established medium-sized studio that does strategic design projects as well as physical/digital products and different kinds of system design (websites, apps etc).

Even though not all design studios are the same - the number of employees, the particular people employed, organizational structure, management, history, culture, type of projects etc matter there seems to be some things that many studios have in common, often being consultants with customer expectations and limitations on time and funding, while working creatively on solutions. They do not always have the space for conversations on ethics, they do not have the habit of including ethical perspectives in their day-today practice, and designers rarely have an educational background in ethics. This was the case at the studio of our choice too, although they are eager to change this and to work towards ethically responsible design - and "we have to start somewhere" [1].

A regular work week in the life of a designer at the studio usually encompasses many different activities, such as e.g. pitching for potential clients, project planning, conducting different forms of design research, doing design sessions alone and/or in groups, and presenting and reviewing/critiquing work. There are also administrative tasks to do, as well as engaging in the development of the studio, and networking online and IRL. At the studio, as in many other design settings, focusing on metrics to define success is a common way of evaluating the work, and a team's metrics guide their most important decisions [15]. This also means that good numbers are often equated with good work. To win design competitions can often also be considered as a mark of excellence. However, the measures and competitions rarely have an ethical focus - at least not yet! A change may be underway, as our introduction indicates, and this particular studio is certainly moving in an ethical direction, having taken several steps already by e.g. doing exercises on ethical dilemmas in design.

\section{METHOD}

When deciding how to design our collaboration with the designers, we found it important to choose ways of working that were familiar to the participants. Based on the literature above, as well as on personal work experience from industry and discussions with our contact person at the studio, we reasoned that the workshop as a format would feel familiar to the designers as well as useful for our research purposes.

Discussing ethics is not something done on a daily basis in design practice. Furthermore, ethics can seem like a daunting area to take on. Therefore, creating a 'safe' place for the exercise was important. As many design studios in Stockholm do, this studio dedicates time for skill development and inspiration. We were able to make use of one of their regular sessions, at the studio premises, for the workshop. This - we thought - would signal of the integration of this activity to the studio's everyday practices, rather than being separate and alien. Our research is inspired by participatory action research in the sense that research has an aim towards change and that the process for change is closely negotiated with the participants as we move along. 


\subsection{Participants}

All workshop participants (15 people) work at the same design studio, described above. Everyone at the studio was invited by way of an internal e-mail sent by a regional director who was our contact when planning the workshop. We deemed the open invitation useful in that it could stimulate people with different roles at the studio to attend, since much design today is done in teams consisting of different roles, not only designers. Also, the title 'designer' means different things to different people, some even argue that any person who partakes in decisions that affect design is a designer $[23,35]$. The people who ended up participating were mostly titled UX and/or Service Designers, probably since most employees at the studio have those roles (we did however not enquire into each individual's skill set and experience). There was an even mix between women and men as well as junior and senior staff attending.

\subsection{The workshop}

Initially the studio asked for a lecture on design ethics. However, since our stance as researchers is that participation and negotiation is crucial when engaging in design ethics, we suggested doing a workshop. We ended up with a lecture-workshop combination, viewing the lecture as a framing introduction to the main event, the workshop.

The studio had a lot of questions surrounding design ethics, which were relayed to us in an e-mail from our contact person at the studio who was suggesting potential topics for the lecture. Some of the questions were about academia and design ethics (translated from the original Swedish), e.g.: 'What is the research area of design ethics about?', 'What are the important design ethics topics for the future?', and 'Why would someone go from design practice to academic research?'. Other questions were about ethics and practice, e.g. 'What does ethics mean in a design context?', 'What ethical dilemmas could a designer find themselves in?', 'How can a designer take ethical responsibility?', and 'Are there any checklists to use?'. These questions were very useful to us when designing the different parts of the lecture and workshop. For example, in the introductory lecture, we talked about the research area of design ethics, brought up examples of what it could mean for a design practitioner, and presented suggestions of e.g. manifestos and guidelines. Their questions also told us about the distance between designers and academia and that the designers have high level of interest and motivation to learn more. While their interest was high, they also expressed lack of confidence and lack of knowledge concerning ethically responsible design.

We had a pre-defined time slot to adapt to, 2 hours, and a meeting room at the studio's premises to use as location. The room has a standard design studio meeting room layout: a large table with chairs surrounding it, a wall for projecting slides, and walls to stick post-its on. The workshop is described in the following sections 4.2.1-4.2.3.

4.2.1 Introductory lecture. After introducing ourselves (two of the researchers involved in this study were facilitating the workshop) and our research, we presented an overview of ethical perspectives in order to create a common vocabulary and starting point. We covered virtue ethics (character traits), consequentialism (consequences/outcomes), Kantian ethics (moral law and human dignity), and applied ethics (e.g. medical ethics or press ethics). Moving on to how practitioners have talked about ethics, we covered the topic of what to design [27] and designer and ethics activist Monteiro's call for designers to take responsibility and suggestion for codes of conduct [23]. Next, we brought up the problems of biased AI leading to e.g. racism and sexism, inclusion and diversity in design practice, and a discussion on values, mentioning Value Sensitive Design as well as feminist values. Lastly, a selection of methods and initiatives were presented, including for example games [22] and manifestos [18] for design ethics.

4.2.2 Ethical challenges. After the introduction, the participants individually brainstormed on what they considered to be ethically challenging related to work and/or what they would like to know more about regarding ethically responsible design. After the individual work, the fifteen participants were divided into three groups of five, to discuss and analyze their individual brainstorms. The goal with the discussion was to negotiate 1-5 areas that the group considered to be the most important. After discussions, the results were presented with all workshop participants present. One group started, clustering their post-its on one of the walls while describing their thinking and choices. Another group followed, adding their post-its, and so on. An oral presentation was given at each round (which we audio recorded), and the session finished by a brief group discussion with all participants.

4.2.3 Co-creating ethical practices. After presentations, participants retreated to individual thinking again, getting 5 sticky dots each to place onto the post-it clusters (figure 1). The dots were used to prioritize the issues they wanted to work with. Participants could either put all the dots on one post-it, or distribute them. The aim with this was to get a visualization of the priorities. The issues that had gained the most votes were: 'When business goals clashes with ethics' (9 dots), 'Designing for good behaviour vs free choice' (8 dots), 'What tools can help me include ethical design in my project?' (8 dots). After voting, participants chose challenges to solve (they did not have to choose the ones with the most votes). For the ideation, they had physical materials such as post-its, papers, stickers (dinosaurs and unicorns!), scissors etc to stimulate creativity and to lower the threshold - since it can be less daunting taking on ethical complexity if the material to work with is well-known and playful. Each group went off designing solutions and came back to present them (we audio recorded these presentations too). Lastly, an evaluation of the workshop was done.

\subsection{Data collection and analysis}

Data from the workshop was documented through audio-recordings from the workshop (which we transcribed), and photographs as well as written field notes. The materials - post-it notes and materializations of ideas for solutions - produced during the workshop constitute a central part of the data giving us direct access to the reasonings of the participants.

All participants consented to the study. Names and elements of the work context are anonymized to protect the participants and 


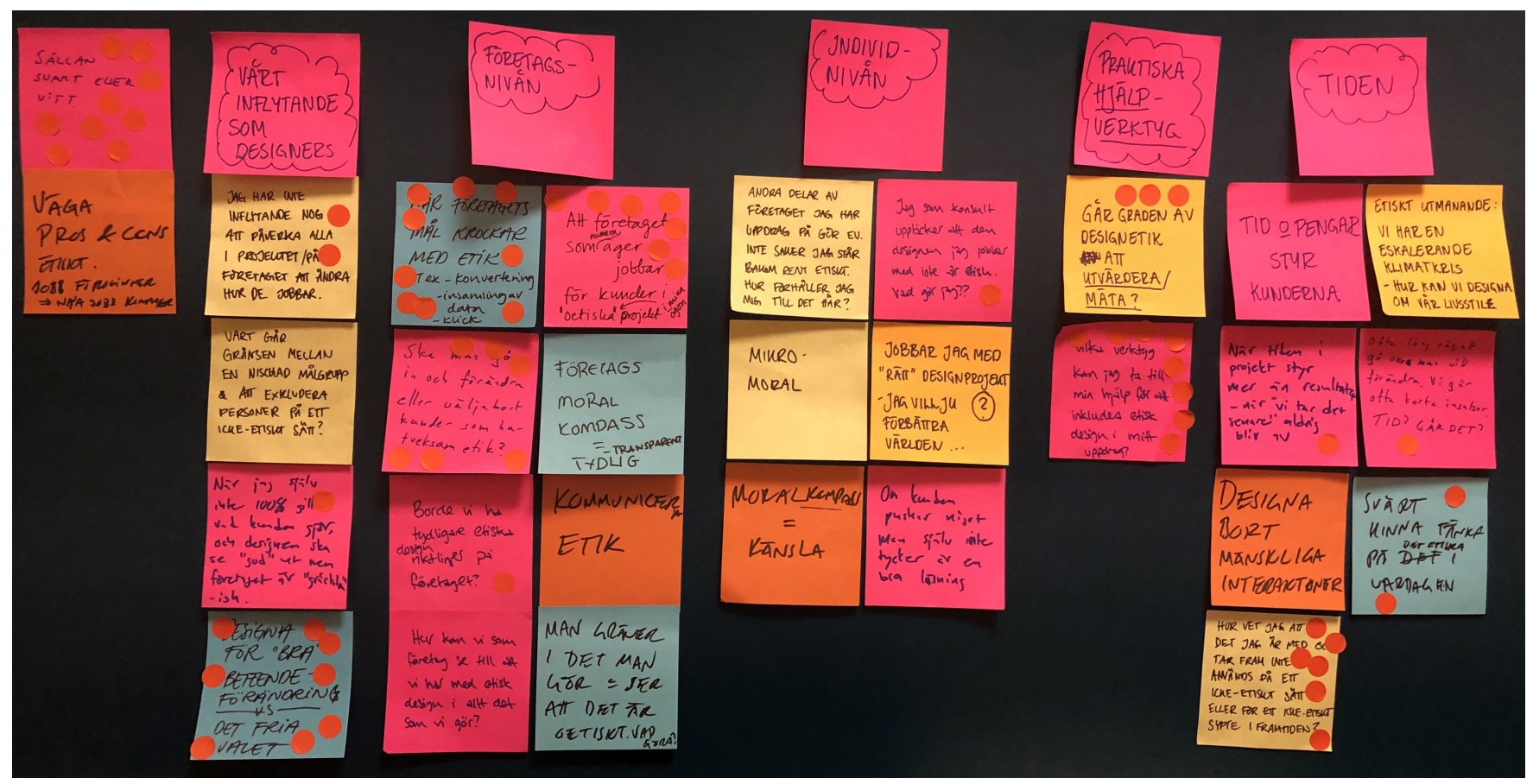

Figure 1: Ethical challenges, prioritized post-its.

their workplace. All the data has been translated into English from the original Swedish.

The rich data from the workshop was organised in a 'data room', to give us a better overview of the diverse data together with related articles and other texts. The transcripts of the presentations were available too. We conducted a qualitative analysis of the data with focus on how designers would conduct cultivation of their own ethical practice, what their starting points would be, and what their solutions and suggestions would look like.

We approached our data looking for possible points of connection between academia and practice. The data analysis followed established procedure for qualitative research, i.e. by conducting iterative and forward-backward movements between the holistic whole and smallest units of analysis (i.e. codes [2]), and by conducting analysis both individually and collectively. The data room was used as a tangible way of reconciling analysts' progress, on holistic as well as detailed levels.

In line with our research question, we were looking for how designers understand and wish to solve ethical issues related to their work. The purpose of this was to expand the knowledge on the perspective on ethics among designers as well as to find potential points of departure for ethos cultivation.

In the presentation of our results we have chosen to use the following three perspectives, stemming from the designers at the workshop: 1) the individual designer, 2) the design studio, and 3) the practice (of designing). In our research question we set out to investigate how designers would conduct cultivation of their own ethical practices. Thus, the individual perspective is important. But as the individuals are also part of a studio it is essential to identify the specific challenges at studio level, too. Thirdly, we present challenges and possible solutions related specifically to the practice of designing as formulated by the participants. The analysis was guided by the perspectives on practice described in 2.1 above - in particular the interrelated constitutive elements of social practices as proposed by Shove, Pantzar, and Watson [34]: material, competence and meaning. However, our focus was on how our participants expressed their own views on design practices, and we therefore used their words rather than ours in the analysis. We will briefly return to Shove et al's framework in our discussion.

\section{RESULTS}

Our data confirmed the notions that there is currently little time and other resources for applying ethics in design practice - the main preoccupations of designers lie in solving design issues for clients, in the project they have at hand. Data also confirmed that the matters of economic interests and short time scales are difficult to handle ethically. An individual designer cannot easily take an ethical stance towards a company-approved but unethical client, and it is hard for individuals to know how to balance long term changes with short term requirements and results. While these findings confirm some of the larger obstacles faced by individuals, our participants also provided important details that may serve as starting points for cultivating ethics.

The latter part of the workshop, where suggestions for ethos cultivation were co-created, proved to be crucial. Our participants confirmed the need for actionable and accessible resources and tools, and provided several starting points and solutions for working with ethics in their own practice. 


\subsection{The designer role}

To cultivate something, the right circumstances need to be provided [40], and what the right circumstances are clearly depends on what is being cultivated. The list below provides an account of how our workshop participants understood and felt about ethics related to the designer role, i.e. potential points of departure for developing the designer role as part of ethos cultivation.

It is interesting and important, but hard to grasp. Our participants view ethics as something they should engage with - they are motivated and interested. However, they found it challenging to know what "ethics" really means in a design context and for a designer. As one participant put it: "To me, ethics is everything and nothing". The meaning of design ethics thus seems unclear, and a lack of knowledge is expressed.

It is not a habit. The workshop confirmed that designers are not in the habit of thinking about ethics. They are not familiar with terms such as 'virtues' or 'values'. The words they use when talking about ethics are rather e.g. 'checklists', 'tools', and 'guidelines'. This aligns with the findings of Colusso et al. [5], stating that practitioners prefer actionable guidance and prescriptive recommendations. Additionally, they are used to working with issues that might not always fit well with an ethical perspective on the project at hand: "clients may want to focus on conversion rates, sales, collecting data, clicks, and then it's hard", said one participant, expressing a wish for knowing more about balancing business goals with ethics.

It can be scary. Being the only person pointing to an ethical problem is not always easy, it takes guts. Since ethics does not yet have a clear place and time in practice, and the role of the designer related to ethics is not clear either, our participants expressed a need for "training" in order to "gain courage and experience for when we are at the clients" and thus make them feel more confident about addressing ethical matters.

\subsection{The design studio}

The following rubrics are the areas discussed by our participants as specific challenges at a studio level, i.e. potential points of departure for cultivating ethos on a studio level.

Choosing clients and projects. Choosing which clients and projects to work with (and not) is deemed an important and challenging choice that an ethically responsible design studio has to deal with. Besides discussing which clients and projects to take on in general, the studio should also have a conversation about what to do if clients, checked off as "good", would start to push for something unethical. Another example was if a designer discovers that the client company she is working for has some unethical business going on outside of the project at hand, for example is making money by cooperating with a totalitarian regime.

What makes the world better? "Am I working on the right projects? I want to make the world a better place!" one participant exclaimed. This has to do with the studio (as most studios) taking on projects that are not apparently "making the world a better place" in the grander scheme of things. One comment was that, "those initiatives don't have the money to hire us", meaning that the "make the world a better place"-projects may not be run by companies with enough money to hire design studios.
Change over time. The projects these designers take on are limited in time, as projects are, but changing things (such as attitudes or practices) usually takes time. This makes it hard to decide on the right way of action if an ethical dilemma emerges.

Studio documents. "Should we have clearer guidelines? We talk quite a lot about ethics, but have not formalized anything". This challenge is about being unsure of the moral position of the design studio. To incorporate moral values in e.g. documented company values would be a way of cultivating the ethos of the company.

Studio culture. "It is not often that you have clear guidelines telling you what to do and not, where the limits are. But you can have this feeling, that this is good, or this is actually not good", said one participant. This feeling (and/or tacit knowledge) obviously stems from personal experiences and knowledge, meaning that the feeling changes over time and could be cultivated into being triggered by new things, for example ethical issues discussed at the studio. A related discussion had to do with what participants named "micro ethics", referring to the different levels of ethics and highlighting that being mindful of the "little things" are important too when cultivating ethos. An example was that instead of saying "time to stretch our legs", saying "time to take a pause" since not all attendants may be able to stretch their legs, due to e.g. paralysis of the legs.

\subsection{The practice}

The studio and its individuals form the context where our participants perform their day to day practices of designing. In the first part of the workshop, participants discussed problems and needs, while the latter part of the workshop concerned co-creating ethical design practices and envisioning solutions. These are more concrete and actionable forms, they are 'seeds' rather than 'soil' - forming points of departure that are applicable to their practice of designing.

Foreseeing future design outcomes. In the 'challenges' part of the workshop, participants discussed the difficulty to foresee future outcomes of design. One example concerned "designing away human interactions" such as designing self-service checkouts, which many stores are switching to instead of having cashiers. These checkouts can have both positive and negative outcomes, making some jobs obsolete, but also possibly creating new jobs as well as good outcomes for stakeholders such as shoppers and shop owners. "I am motivating myself with the possible positive outcomes" said one participant, expressing an unease over the difficulty of foreseeing future implications of design, as well as the difficulty of reflecting over designs that seem "trendy" (such as e.g. self-service checkouts that seem to be everywhere these days).

Prioritizing ethics. Our participants frequently brought up time as a major affecting factor in design work. Time forces one to prioritize what to focus on, often leaving what is perceived as details to later, meaning that some things might be pushed until the time is up and the detail was never dealt with. "Well, time in projects, the project is restrained by time and the result is that 'we'll deal with that later" ". When prioritizing, project related aspects such as money and commerce, new technology, user preferences, client needs etc always appear up front, while other difficult challenges can be postponed, often indefinitely. How to make sure ethical considerations are not put back is a skill that would be good to 


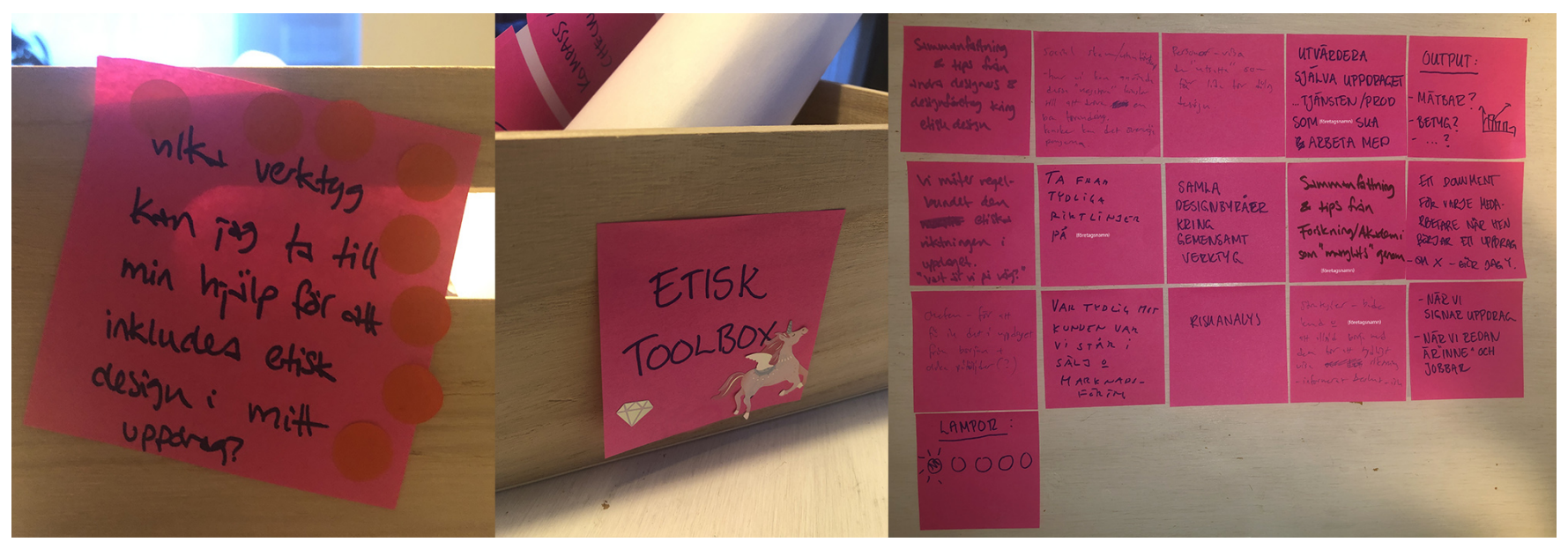

Figure 2: The toolbox (anonymized post-its).

have: "I think the difficult thing is that it's one of very many things to consider, it's time and money of course, you want to to a good job... but these priorities all the time, when you think of ethics [trailing off]".

Tools. Participants saw a need for hands-on tools for working with clients in projects. Ideas suggested already in the 'challenges' phase of the workshop were tools to use, e.g: "Could we for example evaluate or measure how ethical the project is?". Participants expressed that many organisations and companies have a kind of ethical compass in their value statements, which could be used as a tool to relate to ethics in the projects. They also suggested to use risk analysis as an ethical tool to evaluate potential ethical risks of different decisions. Another proposal was to use different kinds of personas as a tool for ethical inclusion, since personas can show "Either that you exclude someone or take steps away from your own strategy, something like that. You're making a decision that doesn't quite go with what you say or how you want to be perceived". Somewhat jokingly, "ethics-shaming" was also brought up, since pointing out unethical design decisions can trigger social shame, which can at times be "worth more than money".

The final part of the workshop concerned the co-creation of ethical design practices; envisioning solutions and 'tools', understood broadly as means for action and ways forward. They were suggested as a way to approach ethical problems as well as a way to integrate ethics into projects. Participants worked in three groups, and each group picked a challenge to work with, stemming from their previously clustered challenges. This resulted in three solutions, presented below.

The toolbox. The challenge picked was: 'What tools can help me include ethical design in my project?'. The envisioned solution was an ethical toolbox for the studio (figure 2). "We created a toolbox, an ethical toolbox for [Studio Name]. We were thinking about the whole process, from sales to like when you work in a project". The toolbox was to be adapted to the specific needs of the design studio, to make sure it is useful: "A moral compass for us consultants. And like a little [Studio Name]-Bible where we can map common scenarios that we run into in assignments".
The group emphasized that they need a range of different tools "because that's the whole idea with a toolbox, it should contain a lot of stuff to dig around in". The toolbox thus has to be dynamic and curated, and with different types of contents for different situations: Learning (education about ethics such as materials to read), examples (best practices related to ethically complicated situations and dilemmas that practitioners can encounter in their projects), measuring/evaluating (ethical barometers and ways of checking for ethical problems), training (roleplay to get prepared for potentially tricky situations and to practice speaking up), guiding materials (formalized and clear guidelines, compasses, checklists), and cooperation (working together with other design studios to create a common approach to ethical design). The purpose of this solution was to make ethics actionable. It taps into a common approach in design practice: using toolboxes. The toolbox was explicitly placed within [Studio Name], pointing out what these designers themselves would find relevant and useful in their practice. Conceivably, it could of course also be useful elsewhere, as challenges, practices and ideas are shared across the design community.

The compass. The challenge picked was: "When business goals clashes with ethics". The solution is a moral compass (figure 3), designed to visualize company ethics. A moral compass is a classical way of talking about ethical behaviour, pointing to what is right and wrong. The compass designed at the workshop was to be used to as a strategic tool as well as to communicate with clients and potential employees, and consists of two parts. First, creating "thermometers" which are areas that the company considers to be ethically important - in this example measuring "Environment", "Equality", and "Accessibility".

Second, the compass itself, where industries, projects and/or clients are placed on a scale of "stuff we do not work with" at one end of the scale, and "the dream project" at the other end. When hiring a new coworker, the compass could be used to communicate the studio's ethical position: "When your come for the interview, you can have a transparent discussion, you can have a compass showing the last couple of months or so, and present it as 'this is our moral compass at [Studio Name]' ". 


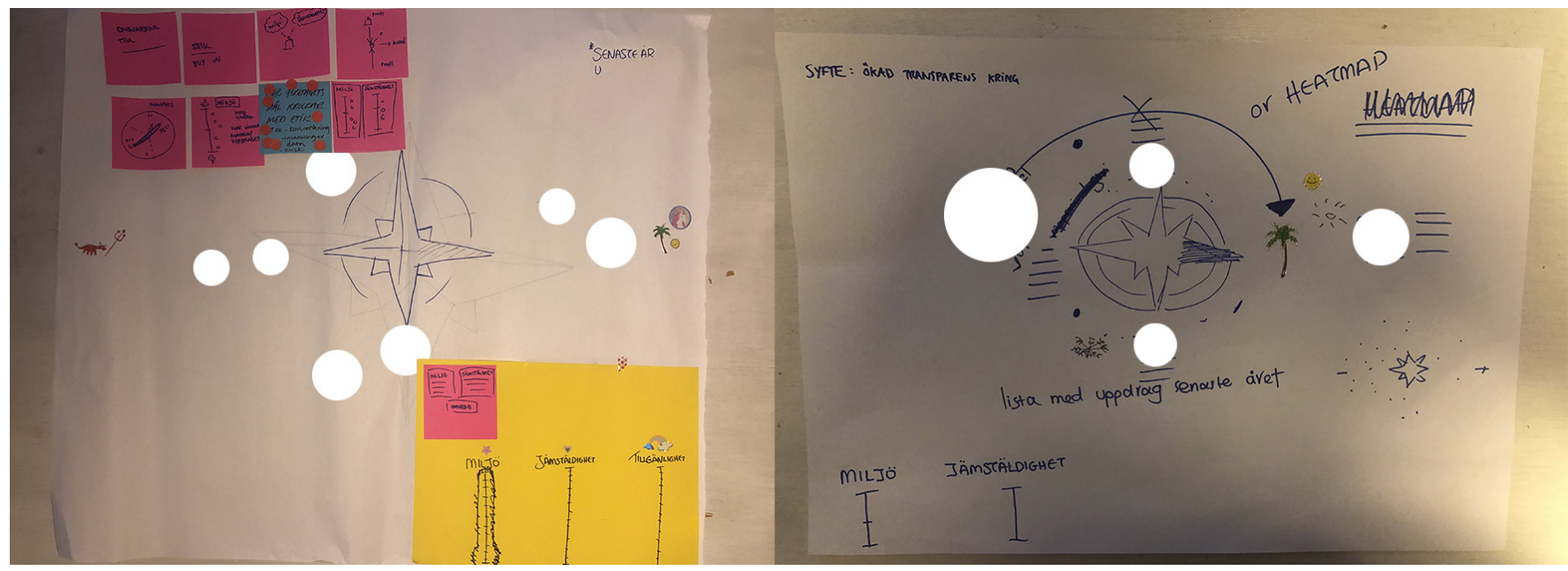

Figure 3: The compass, different versions (white dots to anonymize content).

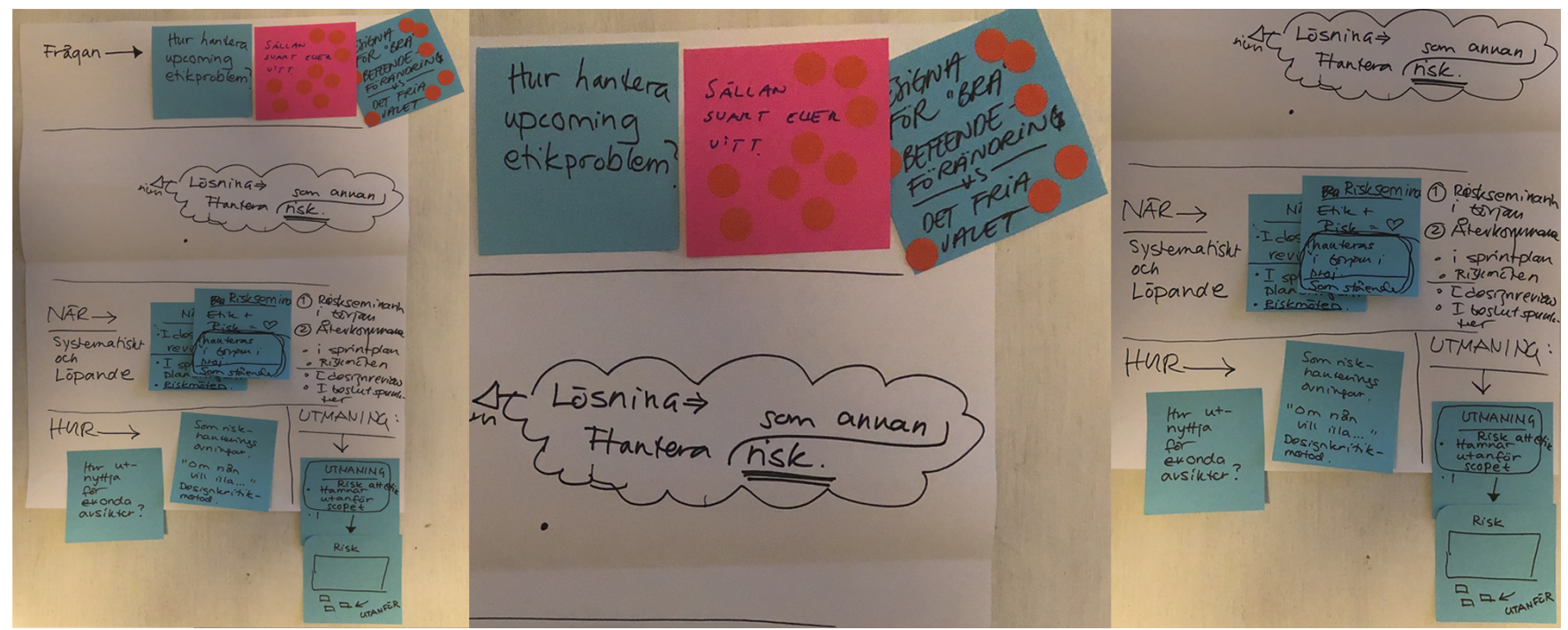

Figure 4: The integrator, overview and details.

It could show e.g. the weapons industry, which would be placed among "stuff we do not work with". On the other end of the compass would be industries, clients or projects that the studio has loved working with or would want to work with (from an ethical point of view). Another way of using the compass is when assessing potential clients/projects to work with: "There's this idea of what [Studio Name] is supposed to be working with, and what we should not work with, and then it would be visible if we are diverting from that. So it can be a way to make sure that [Studio Name] lives up to what was decided". By having the compass as a normative base for reflection, the ethical aspects would be visible and thus easier to discuss and relate to.

The integrator. The challenges picked were: 'Rarely black or white' and 'Designing for "good" behavioural change vs freedom of choice' (not among the top voted issues) but the group came back with a rephrased challenge: 'How to handle problems that comes up during design'. "Many ethical problems emerge during a project, it can be dilemmas and things that you realize underway, and how should we then address the issues continuously?" asked the presenting participant.

To be the one bringing up difficult issues can be a hard role to take on, as also seen in from the challenges part of the workshop. The suggested solution (figure 4) is to treat ethics like any other risk, meaning to view ethical risks as being equally important as e.g. economic ones, and to include ethical considerations during the project by adding it to formalized meetings already taking place - "to make it more systematic". Other already occurring practices that would be suitable for adding an ethical dimension were also suggested, such as sprint planning, design reviews and retrospectives. 
Introducing ethical discussions formally would alleviate the burden on individuals, and have a normative effect by establishing dedicated time and space for ethical issues. "Talking about ethics in the beginning of a project can make it easier to continue talking about it during the project" said one participant, emphasizing that you need to be brave to bring up ethical issues. And ethics needs to be talked about, since "it's a lot about the project, like what's good for the project, how do we get a lot of clicks, that would lead to good metrics here and now". Ethical matters can easily be forgotten, since there are a lot of aspects to consider. The integrator solution aims to solve this problem by adding ethics as a theme into already occurring practices, such as risk management.

\section{TOWARDS ETHOS CULTIVATION IN DESIGN PRACTICE}

The aim of ethos cultivation is to improve ethical practices, something that both scholars and practitioners have expressed a need for doing, as described above. There are obviously different ways of going about this endeavor, a workshop being one way that many designers may feel comfortable to engage with.

\subsection{How would designers conduct cultivation of their own ethical practices?}

The workshop functioned as a way to examine ethos cultivation in design practice. We wanted to examine what designers' starting points would be and what their suggestions for solutions would look like. To continue the gardening metaphor of cultivation: we aimed at making visible the 'soil' (prerequisites and current practices related to ethics), and to find some 'seeds' (ethical issues, starting points) that designers themselves believe should be cultivated.
Looking at our findings through the 'material, competence and meaning'-framework [34], our data suggests a growing interest in, as well as lack of common ground on, what ethically responsible design means. Despite this, many ethical challenges were identified on different levels: related to individual responsibilities, the studio as a whole, and the practice of designing. An overall lack of supporting materials was expressed - there was no clear guidance or system for neither how to understand ethically responsible design nor how to conduct ethical practices. The solutions created at the workshop addressed these issues as in order to scaffold the cultivation of ethical practices, our participants discussed guidelines (e.g. ethical guidelines and formal documents) as well as tools (e.g. the ethical toolbox and compass). These materials would increase competence (skills) and shape meaning (understandings), while meaning and competence shape the materials.

Our study confirms previous findings that for solutions to suit the life-world of design practitioners they need to be actionable and fit into the design process used in industry [5]. Clearly they also need to address issues that designers perceive as problematic, such as e.g. how to choose ethical clients or making sure that ethical issues in projects are dealt with. Solutions should also be be easy to visualize, to use, and to explain to stakeholders [5], which is evident looking at the ones created at our workshop.

\subsection{Actionable ethics}

Through our analysis of the workshop we have aimed at finding applicable points of departure ('seeds') for ethos cultivation. We have translated our findings into a set of questions (table 1) in order to increase the visibility of ethical issues in practice, and to stimulate further discussions on ethics.

\section{Table 1: Actionable ethics}

The design studio What do we as a company consider to be ethical/unethical and why?

Do we have any guidelines to guide us on ethics?

Should we formalize anything in regard to ethics?

How do we choose our clients and projects?

Are there industries or projects we would never take on?

What would a "dream client" be for us, from an ethical perspective?

How and when do we talk about ethics at the studio?

How and when do we talk about ethics with our clients?

How do we collect and share knowledge on ethics?

How do we present our ethical stance to new colleagues?

How do we keep the conversation on ethics going?

The practice

How could we foresee and minimize the risk of "bad things" happening because of what and how we design? How could we make sure that ethical considerations in our projects are not ending up in the "later pile" and thus not dealt with?

What tools can help to include ethical design in the projects? 
Our data suggests that it is important to align ethos building closely with other design activities, and with some explicit decrees and social agreements. The suggested set of questions is intended to spark conversation and elicit participation. Not all of them are to be used simultaneously - some of the questions are better suited for discussion and activities related to competence development, and some for development of the studio or particular design processes.

In accord with Colusso et al. [5], we have strived for presenting the questions in a form that could easily be plugged into design processes in the industry, as a resource that is uncomplicated to visualize, use and explain - thus making them actionable. The questions are grouped under the three rubrics 'the designer role', 'the design studio' and 'the practice', building on our analysis above. By formulating questions rather than prescriptive tasks, the intent is to stimulate conversations around the topics that our participants found important and challenging, while avoiding managerial top-down approaches. The questions themselves stem from the particularities in each area presented above, i.e. what designers considered to be important and challenging.

\section{IMPLICATIONS AND FUTURE WORK}

The questions that we have presented lay out areas considered important and challenging to designers. These are evolving and malleable, and so other studies in other contexts may yield further elements to consider. Future studies should engage in further exploring the cultivation of ethos in various contexts.

Our study was conducted in Sweden. Further international research would account for cultural differences and contribute to our understandings of contextual issues. For example, Swedish workplaces are known for flat organisational structures, thus sometimes allowing workers to e.g. refuse certain projects and to voice their opinions in ways that might be even harder in more hierarchical organizational cultures. Also, designers with employers other than design studios, e.g. in-house, governmental institutions, NGO:s etc, may provide other accounts than the ones given here.

Our study adds to previous practice-first work in design of e.g. Gray and Chivukula [14] and Colusso et al. [5]. Our results could be helpful in bridging the research-practice gap, described by e.g. Colusso et al. [5], and to be used as e.g. input in translational processes, theory creation or method development, as well as for practitioners who are interested in cultivating ethical practices, since the questions should be tapping into relevant issues for them. (However, since practitioners are not in the habit of using academic resources [5], the findings should also need to be published in a more designerly venue in order to reach them.)

The workshop format we used for data collection could in itself be viewed as a component for ethos building in design practice. The results expand our knowledge of ethical problems from the practitioners' point of view, as well as our knowledge of practiceled solutions. Based on the knowledge and experiences of these practitioners, we have proposed a set of questions that would be helpful in summarizing the ethical understandings of designers. These questions can be used as a foundation for future work on better supporting application of ethics in design practice contexts.

\section{ACKNOWLEDGMENTS}

We thank the participating designers for their time and engagement in the workshop, sharing their thoughts, feelings and experiences with us. We also wish to thank Teresa Ceratto-Pargman, Stockholm University, for helpful methodological discussions and insights on practice theories, and Ola Knutsson, Stockholm University, for constructive and inspiring conversations about designing workshops. Lastly, we wish to thank our anonymous reviewers for their kind, thoughtful, and very valuable comments and suggestions.

\section{REFERENCES}

[1] Cennyd Bowles. 2019. Future Ethics. https://www.youtube.com/watch?v= DfxMv9mIjFU\&feature $=$ youtu.be

[2] Virginia Braun and Victoria Clarke. 2006. Using thematic analysis in psychology. 3, 2 (2006), 77-101. https://doi.org/10.1191/1478088706qp063oa

[3] Hooper CJ Buie, Elizabeth and Houssian Aaron. 2013. Research-practice interaction: building bridges, closing the gap. https://doi.org/10.1145/2468356.2468813

[4] Jeffrey K.H. Chan. 2018. Design ethics: Reflecting on the ethical dimensions of technology, sustainability, and responsibility in the Anthropocene. 54 (2018), 184-200. https://doi.org/10.1016/j.destud.2017.09.005

[5] Lucas Colusso, Cynthia L. Bennett, Gary Hsieh, and Sean A. Munson. 2017. Translational Resources: Reducing the Gap Between Academic Research and HCI Practice. In Proceedings of the 2017 Conference on Designing Interactive Systems DIS '17 (Edinburgh, United Kingdom). ACM Press, 957-968. https://doi.org/10. $1145 / 3064663.3064667$

[6] Jessica Nihlen Fahlquist, Neelke Doorn, and Ibo van de Poel. 2014. Design for the Value of Responsibility. In Handbook of Ethics, Values, and Technological Design, Jeroen van den Hoven, Pieter E. Vermaas, and Ibo van de Poel (Eds.). Springer Netherlands, 1-15. https://doi.org/10.1007/978-94-007-6994-6_18-1

[7] Trine Falbe. 2018. Ethical Design: The Practical Getting-Started Guide. (2018). https://www.smashingmagazine.com/2018/03/ethical-design-practicalgetting-started-guide/

[8] ACM The Association for Computing Machinery. 2018. ACM Code of Ethics and Professional Conduct. https://www.acm.org/binaries/content/assets/about/acmcode-of-ethics-booklet.pdf

[9] Nätverket Tech for Good. 2016. Tech for Good. https://www.techforgood.se

[10] Christopher Frauenberger, Marjo Rauhala, and Geraldine Fitzpatrick. 2016. InAction Ethics. (2016). https://doi.org/10.1093/iwc/iww024

[11] Batya Friedman, Peter H Kahn, and Alan Borning. 2002. Value Sensitive Design: Theory and Methods. (2002), 8.

[12] Ken Friedman. 2012. Models of Design: Envisioning a Future Design Education. (2012), 22.

[13] Jet Gispen. 2017. Ethics for Designers. https://www.ethicsfordesigners.com/

[14] Colin M. Gray and Shruthi Sai Chivukula. 2019. Ethical Mediation in UX Practice. In Proceedings of the 2019 CHI Conference on Human Factors in Computing Systems - CHI '19 (Glasgow, Scotland Uk, 2019). ACM Press, 1-11. https://doi.org/10. $1145 / 3290605.3300408$

[15] Lu Han. 2019. Designing for Tomorrow - A Discussion on Ethical Design. https://spotify.design/articles/2019-01-18/designing-for-tomorrow-adiscussion-on-ethical-design/

[16] Sven Ove Hansson (ed.). 2017. The Ethics of Technology-Methods and Approaches. Rowman \& Littlefield International.

[17] Tristan Harris, Aza Raskin, and Randima Fernando. 2019. Center for Humane Technology. https://humanetech.com

[18] Laura Kalbag and Aral Balkan. 2017. Ethical Design Manifesto by ind.ie. https: //2017.ind.ie/ethical-design/

[19] Kolko, John. 2013. UX Magazine. http://www.jonkolko.com/writingManipulation. php

[20] Kari Kuutti and Liam J. Bannon. 2014. The turn to practice in HCI: towards a research agenda. In Proceedings of the 32nd annual ACM conference on Human factors in computing systems - CHI '14 (Toronto, Ontario, Canada). ACM Press, 3543-3552. https://doi.org/10.1145/2556288.2557111

[21] Sapna Maheshwari. 2017. That Game on Your Phone May Be Tracking What You're Watching on TV. (2017). https://www.nytimes.com/2017/12/28/business/ media/alphonso-app-tracking.html

[22] Microsoft Design. 2019. Judgement Call. https://twitter.com/microsoftdesign/ status/1093607842928574464

[23] Mike Monteiro. 2019. Ruined by Design. Mule Design.

[24] Cosmin Munteanu, Heather Molyneaux, Wendy Moncur, Mario Romero, Susan O'Donnell, and John Vines. 2015. Situational Ethics: Re-thinking Approaches to Formal Ethics Requirements for Human-Computer Interaction. In Proceedings of the 33rd Annual ACM Conference on Human Factors in Computing Systems CHI '15 (Seoul, Republic of Korea, 2015). ACM Press, 105-114. https://doi.org/ 
$10.1145 / 2702123.2702481$

[25] Nodder, Chris. 2013. Evil By Design. Wiley.

26] Donald A. Norman. 2010. The Research-Practice Gap: The Need for Translational Developers. (2010). https://doi.org/10.1145/1806491.1806494

[27] Papanek, Viktor. 1972. Design for the real world; human ecology and social change. https://monoskop.org/images/f/f8/Papanek_Victor_Design_for_the_ Real World.pdf

[28] Andrew Pickering. 1995. The Mangle of Practice : Time, Agency \& Science. The University of Chicago Press.

[29] The Consentful Tech Project. 2019. The Consentful Tech Project. http://www consentfultech.io

[30] Gauthier Roussilhe. 2017. Ethics for Design. http://ethicsfordesign.com/watch

[31] Knorr Cetina Karin \& Savigny Eike von (Eds.) Schatzki, Theodore R. 2001. The practice turn in contemporary theory. Taylor \& Francis Group.

[32] Katie Shilton. 2013. Values Levers: Building Ethics into Design. 38, 3 (2013), 374-397. https://doi.org/10.1177/0162243912436985

[33] Katie Shilton. 2018. Values and Ethics in Human-Computer Interaction. Foundations and Trends in Human-Computer Interactions, Vol. 12:2. now Publishers
Inc.

[34] Shove, Elizabeth, Pantzar, Mika, and Watson, Matt. 2012. The Dynamics of Social Practice: Everyday Life and How it Changes. SAGE Publications Ltd. https: //doi.org/10.4135/9781446250655

[35] Jared Spool. 2017. The Power of Experience Mapping. https://medium.com/ @jmspool/the-power-of-experience-mapping-212ba81e5ee

[36] Aimee van Wynsberghe and Scott Robbins. 2014. Ethicist as Designer: A Pragmatic Approach to Ethics in the Lab. 20, 4 (2014), 947-961. https: //doi.org/10.1007/s11948-013-9498-4

[37] Peter-Paul Verbeek. 2005. What Things Do. Pennsylvania State University Press.

[38] Peter-Paul Verbeek. 2011. Moralizing Technology - Understanding and Designing the Morality of Things. University of Chicago Press.

[39] Kenneth D. Walsh. 2007. On equilibrium: reflections on practice development and the philosophy of John Ralston Saul. 8, 3 (2007), 201-209. https://doi.org/10. 1111/j.1466-769X.2007.00314.x

[40] Etienne Wenger, Richard A. McDermott, and William Snyder. 2002. Cultivating communities of practice: a guide to managing knowledge. Harvard Business School Press. 